\title{
INATIVAÇÃO FOTODINÂMICA DE MICRORGANISMOS
}

\author{
Janice Rodrigues Perussi \\ Instituto de Química de São Carlos, Universidade de São Paulo, CP 780, 13560-970 São Carlos - SP, Brasil
}

Recebido em 20/6/06; aceito em 18/12/06; publicado na web em 28/5/07

\begin{abstract}
PHOTODYNAMIC INACTIVATION OF MICROORGANISMS. Photodynamic Therapy uses photosensitive dyes and visible light that, combined in the presence of oxygen, produce cytotoxic species that cause tumor death. Microorganisms such as bacteria, fungi, yeasts and viruses (including HIV) can also be inactivated by visible light after treatment with an appropriate photosensitizer as an alternative low cost treatment for localized infections, viral lesions such as acnes, and fungical skin lesions for example. Besides, Photodynamic Inactivation can be used for sterilization of blood and its subproducts for clinical use, in the treatment of drinking water as well as in antimicrobial detoxification of foods.
\end{abstract}

Keywords: photodynamic inactivation; microorganisms; dyes.

\section{INTRODUÇÃO}

A Terapia Fotodinâmica (TFD) baseia-se na administração tópica ou sistêmica de um corante não tóxico sensível à luz seguida da irradiação em baixas doses com luz visível de comprimento de onda adequado $^{1}$. Na presença de oxigênio encontrado nas células, o fotossensibilizador (FS) ativado pode reagir com moléculas na sua vizinhança por transferência de elétrons ou hidrogênio, levando à produção de radicais livres (reação do tipo I) ou por transferência de energia ao oxigênio (reação do tipo II), levando à produção de oxigênio singlete. Ambos os caminhos podem levar à morte celular e à destruição do tecido doente ${ }^{2,3}$. O oxigênio singlete reage com quase todos os componentes celulares uma vez que os compostos orgânicos insaturados são, de forma geral, suscetíveis à ação de ${ }^{1} \mathrm{O}_{2}$. Como a primeira barreira para o ${ }^{1} \mathrm{O}_{2}$ é a membrana celular e esta contém lipídeos insaturados que podem ser danificados, ocorre a inviabilidade celular. Os hidroperóxidos resultantes podem levar à formação de espécies reativas de oxigênio (ROS) através de reações catalíticas. Uma vez que a reatividade das ROS com moléculas orgânicas não é específica, qualquer macromolécula dentro da célula pode ser um alvo em potencial para TFD. Assim, a multiplicidade de alvos torna mais difícil para as células desenvolverem resistência celular, sendo essa uma das vantagens da fotossensibilização, além da morte celular ${ }^{4}$.

Reações tipo I: formação de radicais livres $\left({ }^{\circ} \mathrm{OH}\right)$ através da transferência de elétron entre o FS no estado triplete excitado e componentes do sistema, gerando ânion-radical superóxido $\left({ }^{\circ}{ }_{2}^{-}\right)$.

$\mathrm{O}_{2} \rightarrow \mathrm{O}^{-}$

$\mathrm{O}_{2}^{-}+{ }^{*} \mathrm{O}_{2} \rightarrow \mathrm{H}_{2} \mathrm{O}_{2}+\mathrm{O}_{2}$

$\cdot \mathrm{O}_{2}^{-}+\mathrm{H}_{2} \mathrm{O} \rightarrow \mathrm{O}_{2}+\mathrm{OH}^{-}+{ }^{\cdot} \mathrm{OH}$

Reações tipo II: transferência de energia ${ }^{5}$ do FS no estado triplete $\left({ }^{3} \mathrm{~S}_{1}{ }^{*}\right)$ com formação de oxigênio singlete $\left({ }^{1} \mathrm{O}_{2}\right)$

${ }^{1} S_{0} \stackrel{h v}{\longrightarrow}{ }^{1} S_{1}^{*} \stackrel{I S C}{\longrightarrow}{ }^{3} S_{1}^{*}$
${ }^{3} S_{1}^{*}+{ }^{3} O_{2} \rightarrow{ }^{1} S_{0}+{ }^{1} O_{2}$

e-mail: janice@iqsc.usp.br
Outras vantagens da TFD são: ser efetiva teoricamente em todos os tipos de câncer, dispensar a especificidade dos agentes quimioterapêuticos e a radiação ionizante ${ }^{3}$. Comparada com outras terapias citotóxicas, TFD tem a vantagem de dupla seletividade: não apenas o FS pode ser direcionado para as células ou tecido doente, mas também a luz pode ser precisamente focalizada no local da lesão $0^{6,7}$. O procedimento pode ser repetido várias vezes, se necessário, uma vez que não há efeitos tóxicos cumulativos e é usualmente não invasivo. Além disso, devido ao seu baixo risco, pode ser usado em pessoas idosas ou que estão debilitadas demais para serem submetidas a uma cirurgia. $\mathrm{O}$ principal efeito colateral é a sensibilização à luz, que é contornada evitando exposição à luz solar e luz interna muito intensa por um período de até 6 semanas, dependendo do $\mathrm{FS}^{8}$. De modo geral, o FS é injetado na corrente sanguínea e, dependendo do tipo de corante, é absorvido por células de todo o corpo. O FS é escolhido pela sua farmacocinética a fim de favorecer sua permanência nas células tumorais por um período de tempo maior que nas células normais, embora o mecanismo dessa retenção ainda não seja bem entendido. A ativação com luz é realizada apenas quando praticamente todo FS deixou as células normais, mas ainda está presente nas células cancerosas, levando então à reação fotodinâmica. A resposta do tumor à TFD também não está completamente entendida, mas alguns aspectos já estão bem estabelecidos. A efetividade da TFD depende dos eventos que estão ocorrendo nas células malignas bem como na vascularidade do tumor. Esses eventos podem resultar em estase do fluxo sanguíneo, colapso vascular e, neste caso, a morte celular pode ocorrer por necrose. A morte celular pode também ocorrer mediada por apoptose. TFD tem sido também usada com bons resultados contra tumores com o fenótipo chamado resistência a multifármacos (MDR), ou seja, resistente a uma grande variedade de fármacos estrutural e funcionalmente não relacionados ${ }^{8}$. TFD já foi aprovada para tratamento de vários tipos de câncer como de bexiga, pulmão, esôfago, gástrico e cervical, além de degeneração macular relacionada à idade. Outras aplicações não oncológicas de TFD em estágio menos desenvolvido incluem tratamento de lesões pré-malignas, psoríase, artrite, Barret's de esôfago, aterosclerose e restenose tanto em veias como em artérias?.

Microrganismos tais como bactérias, fungos, leveduras e vírus também podem ser mortos por luz visível depois de tratamento com um FS apropriado e luz, em um processo denominado Inativação Fotodinâmica ("PDI, Photodynamic Inactivation") ${ }^{1}$ ou Quimioterapia 
Fotodinâmica Antimicrobiana ("PACT, Photodynamic Antimicrobial Chemotherapy") $)^{9}$. Neste texto será adotado o termo PDI.

Há mais de cem anos Raab publicou o primeiro artigo sobre efeitos fotodinâmicos de compostos químicos (eosina e alaranjado de acridina, Figura 1) contra microrganismos ${ }^{10}$. Ele observou a toxicidade do hidrocloreto de acridina contra Paramecium caudatum. Mais tarde, von Tappeiner relatou que esses efeitos tóxicos não se deviam apenas à presença da luz e criou o termo "reação fotodinâmica" ". Vinte anos depois, Policard publicou as primeiras observações clínicas ${ }^{12}$. A aplicabilidade dessa técnica foi demonstrada em bactérias, vírus e protozoários bem antes da Segunda Guerra, mas foi abandonada devido à popularização das sulfonamidas e da penicilina ${ }^{13}$. O retorno da aplicação antimicrobiana de FS na última década é resultado de dois fatores: a disseminação da AIDS devido ao HIV e o enorme crescimento das infecções hospitalares devido às bactérias resistentes aos fármacos. A evolução microbiana é muito mais rápida que a do homem e o que tem ocorrido recentemente nos hospitais é decorrente do princípio de sobrevivência dos mais adaptados. As bactérias patogênicas, que em pequena porcentagem são naturalmente resistentes a fármacos (tais como penicilinas), logo se tornam a população dominante. Uma vez que FSs agem via produção de oxigênio singlete, não existe resistência microbiana natural, assim, não importa se a cepa é resistente a uma ou muitas classes de agentes antibacterianos (por ex. Staphylococcus aureus são resistentes à meticilina), dado que o FS é capturado pelo micróbio.

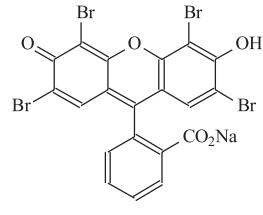

A

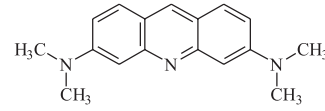

B
Figura 1. Estrutura química da eosina $Y(A)$ e do alaranjado de acridina (B)

Embora o princípio fotoquímico seja o mesmo para câncer e TFD antimicrobiano, existem diferenças importantes nas estruturas dos FS e alvos celulares. A maioria dos FS que estão sendo usados clinicamente ou investigados para tratamento do câncer e outras doenças são baseados em núcleos tetrapirrólicos incluindo porfirinas (Figura 2), clorinas, bacterioclorinas e ftalocianinas (Figura 3) devido a sua baixa toxicidade na ausência de luz em células de mamíferos e por suas propriedades de localização de tumor.

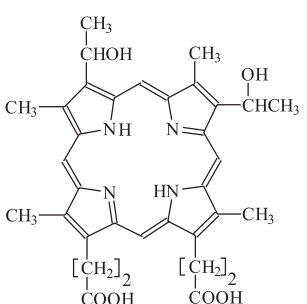

A

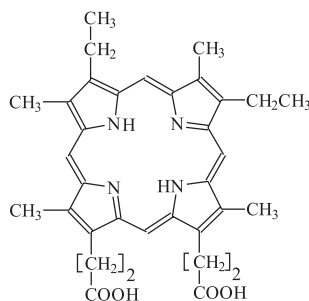

$\mathrm{B}$
Figura 2. Estrutura química da hematoporfirina (A) e da protoporfirina (B)

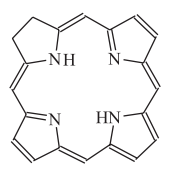

A

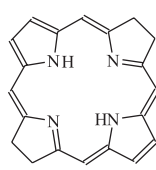

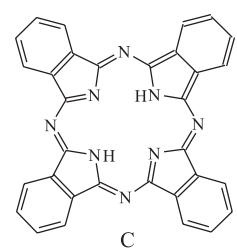

$\mathrm{C}$
Os fotossensibilizadores que têm sido estudados para erradicação de microrganismos pertencem a diferentes grupos de compostos, por ex., os xantenos halogenados tais como Rosa de Bengala (RB), fenotiazínicos tais como azul de toluidina $\mathrm{O}$ (TBO) e azul de metileno (AM) (Figura 4), acridinas e conjugados de clorina $\left(\mathrm{e}_{6}\right)^{13}$.<smiles></smiles><smiles></smiles><smiles></smiles>

Figura 4. Estrutura química da Rosa de Bengala (A), azul de toluidina $O$ (B) e azul de metileno $(C)$

A síntese do corante fenotiazínico AM foi descrita por Caro em 1876, e seu uso como um fármaco antimalárico por Ehrlich 15 anos depois. Em termos de pesquisa de medicamentos, isso torna o sistema anel fenotiazínico um dos heterociclos estabelecidos há mais tempo e a síntese química dos fenotiazínicos é bem entendida, permitindo fácil preparação de análogos. É bem estabelecido que o cátion AM intercala na estrutura do ácido nucléico devido à carga positiva e suficiente área de superfície planar do FS em questão ${ }^{14}$. Entretanto, esse cromóforo facilmente sofre redução por sistemas biológicos e assim, sua atividade antibacteriana é baixa. $\mathrm{O}$ alaranjado de acridina é bioisóstero do AM, diferindo somente pela ausência do enxofre no anel central sem alterar a planaridade da estrutura e mantendo o valor do $\mathrm{pK}_{\mathrm{a}}$ elevado, propriedades necessárias para intercalar no DNA. Foi relatado que a metilação cromofórica do AM diminui a tendência à redução ${ }^{13}$. Foi descrito um estudo com AM em tumores colorretais experimentais de camundongo em que foi concluído que existe uma dose limiar para o AM que previne o dano oxidativo no tecido ${ }^{15}$.

Hamblin e colaboradores defendem a hipótese de que os fotossensibilizadores antimicrobianos podem ser divididos em três grupos: os que estão fortemente ligados e penetram nos organismos (por ex., a clorina $\mathrm{e}_{6}$ ), os que estão ligados fracamente (por ex., TBO) e os que não demonstram ligação (por ex., RB) ${ }^{3}$.

Os principais alvos para TFD em células de mamíferos são lisossomos, mitocôndrias e membranas plasmáticas, enquanto em células microbianas o dano à membrana externa desempenha um papel importante, pois pode impedir o dano ao DNA. PDI tópico pode ser usado ainda para infecções em tecidos não perfundidos, tais como queimaduras, e pode ter menos toxicidade quando comparado com outros tratamentos antimicrobianos tópicos ${ }^{6}$.

\section{Bactérias}

Apesar do considerável progresso que tem sido obtido nos tratamentos de infecções, é preocupante o crescente número de bactérias patogênicas resistentes a antibióticos no mundo todo ${ }^{16}$, o que, segundo Hamblin e Hasan 7 , pode levar ao fim de um extenso período que inclui os últimos 50 anos, chamado de "era do antibiótico". As bactérias multiplicam-se muito rapidamente e uma mutação que ajude um único micróbio a sobreviver na presença de um antibiótico rapidamente se tornará predominante na população microbiana. Assim, é importante se encontrar novas técnicas antimicrobianas contra a qual a bactéria não seja capaz de desenvolver resistência ${ }^{3}$. A PDI
Figura 3. Estrutura química das clorinas (A); bacterioclorinas $(B) e$ ftalocianinas $(C)$ 
tem sido proposta como uma terapia antibacteriana alternativa ${ }^{1,17}$. A PDI, sendo efetiva contra vírus, bactérias e fungos, pode ser usada como uma terapia para infecções localizadas. Em contraste com a TFD de câncer, onde o FS usualmente é injetado na corrente sanguínea e se acumula no tumor, a PDI pode ser feita por aplicação local do FS na área infectada por aplicação tópica, instilação, injeção intersticial ou aerosol ${ }^{7}$. Foi mostrado que, in vivo, PDI reduz tremendamente os micróbios com pequeno efeito nos queratinócitos, constituindo-se assim uma alternativa segura para o tratamento antimicrobiano convencional. Ao mesmo tempo, não se tem notícia de desenvolvimento de resistência microbiana à PDI e é improvável que seja desenvolvida ${ }^{7}$.

Com relação à eficiência da inativação bacteriana, é conhecido que bactérias Gram-positivas (+) são geralmente mais susceptíveis à PDI e as espécies Gram-negativas (-) são significantemente resistentes a muitos fotossensibilizadores comumente usados em TFD de tumores ${ }^{16}$.

Essas diferenças podem ser explicadas pelas diferenças estruturais nas paredes das células. Uma vez que a coloração de Gram age de forma similar a muitos FS usados em TFD, pode-se imaginar que as espécies Gram (+) que facilmente capturam o corante são também facilmente mortas, enquanto o reverso é verdadeiro para bactéria Gram (-) $)^{3}$. O envelope celular das bactérias Gram (-) tem uma membrana externa complexa incluindo duas bicamadas lipídicas que funcionam como uma barreira física e funcional entre a célula e seu ambiente, enquanto as células Gram (+) têm somente uma membrana que é relativamente permeável. Fungos, tais como Candida albicans, são ainda mais resistentes à PDI devido à presença de uma membrana nuclear que pode representar uma barreira adicional à penetração do $\mathrm{FS}^{3}$.

Essa resistência tem sido superada pelo uso de conjugados de FS com polímeros catiônicos ou por coadministração de peptídeos permeabilizantes. Portanto, FS positivamente carregados são geralmente mais eficientes em bactérias e agem em concentrações menores que as moléculas de FS neutras e aniônicas ${ }^{1}$.

Diferenças na susceptibilidade à PDI entre espécies de bactéria da mesma classificação Gram dependem de fatores que podem ser peculiaridades das barreiras de permeabilidade das membranas mas também de diferenças nas enzimas antioxidantes no DNA ou mecanismos de reparo do DNA bem como de fatores simples, tais como tamanho da célula microbiana ${ }^{6}$. Além disso, são importantes as características de cada FS. A hidrofobicidade e a presença de cargas nos FSs levam a diferentes interações com as organelas. Desse modo, a ação fotodinâmica de um corante positivo pode ocorrer na mitocôndria, enquanto que a de um corante negativo pode ocorrer na membrana nuclear para uma mesma classe de bactérias, por ex. ${ }^{18}$.

Foi mostrado recentemente que $H$. pilori acumula naturalmente porfirina suficiente para permitir fotoinativação com luz azul $^{7}$. H. pilori é uma bactéria patogênica endêmica que causa ulceração gastroduodenal em humanos e está ligada ao desenvolvimento de câncer de estômago. Tem sido descrito o aparecimento de resistência a antibióticos na terapia convencional com três fármacos. Em um teste clínico preliminar em 13 pacientes usando-se administração oral de ácido 5-aminolevilínico (ALA) e iluminação da porção gástrica após 45 min com um laser azul acoplado a um endoscópio. A erradicação dessa bactéria por PDI foi constatada através de biópsia ${ }^{19}$.

De modo similar a muitas células de mamíferos, a maioria das bactérias usam o caminho biossintético do heme para produzir porfirinas a partir do precursor ALA. A acne é causada pelo crescimento da $P$. acnes nas glândulas sebáceas e essas bactérias acumulam porfirinas que fluorescem no vermelho; essa propriedade tem sido usada como base para o tratamento fototerápico da $a c n e^{20}$. PDI com aplicação tópica de ALA e aplicação de luz vermelha foi testada em 22 pacientes com acne vulgaris nas costas. Foi observada a eliminação da acne inflamatória que persistiu por pelo menos 20 semanas $^{21}$.

\section{Fungos e leveduras}

O interesse na PDI de leveduras foi inicialmente baseado no papel das leveduras como um organismo modelo. Elas são fáceis de cultivar e podem ser usadas em estudos que são complicados demais para serem feitos com células superiores. Leveduras, tais como Saccharomyces marxianus têm sido usadas como organismos-modelo para acessar o dano celular por PDI em células eucarióticas².

$\mathrm{O}$ interesse por tratamentos fungicidas eficientes vem aumentando recentemente, devido ao crescente número de patógenos fúngicos causados pela ocorrência maior de infecções nosocomiais ou micoses oportunistas em pacientes imunocomprometidos. Infelizmente, agentes seguros e específicos são escassos e a maioria deles é somente fungistática, ou seja, não provocam a morte, apenas inibem a multiplicação. Além disso, o uso rotineiro de antibioticoterapia leva progressivamente ao aparecimento de linhagens resistentes ${ }^{4}$. Com isso, tem havido um interesse renovado por PDI em fungos ${ }^{22}$ e o alvo tem sido principalmente no uso de PDI para fungos patogênicos ou potencialmente patogênicos, como Aspergillus fumigatus, Trichophyton rubrum e especialmente Candida albicans que é um habitante comum da boca, garganta, trato digestivo e pele. Em hospedeiros com um sistema imune comprometido este fungo pode se tornar patogênico e por essa razão candidíase orofaringeana é uma das infecções oportunistas que acometem pacientes com $\mathrm{AIDS}^{2}$. A resistência de cepas de $C$. albicans contra fluconazol, um agente antifúngico freqüentemente usado por esses pacientes, tem começado a aparecer ${ }^{23}$.

A maioria dos estudos investigando os mecanismos de PDI de fungos tem usado como fotossensibilizadores hematoporfirinas aniônicas e seus derivados, clorinas ${ }^{22}$, ftalocianinas Cl-Al hidrofóbicas, o corante catiônico tiazínico azul de toluidina e porfirinas cationicas, sendo que neste caso foi observado que a membrana citoplasmática é a estrutura alvo².

Há um número menor de estudos sistemáticos com fungos e leveduras comparado aos estudos com bactérias investigando as características moleculares necessárias ao FS para que seja efetivo em mediar PDI em várias espécies de microorganismos?

\section{Vírus}

A maioria dos trabalhos em que a metodologia visa a esterilização do sangue e dos produtos do sangue in vitro tem como alvo vírus. Da mesma forma a maioria das aplicações clínicas de PDI para infecções localizadas tem sido voltada para lesões de etiologia viral ${ }^{7}$.

No tratamento de papiloma vírus (HPV), a PDI tópica ou sistêmica tem se mostrado eficiente, já que terapias convencionais não conseguem prevenir recorrências múltiplas. A PDI usando éter de diematoporfirina foi testada em 48 pacientes e apresentou decréscimo significante na taxa de crescimento do papiloma, a qual se manteve por 3 anos em acompanhamento ${ }^{24}$.

$\mathrm{O}$ primeiro estudo para examinar a eficácia de porfirinas na inativação de patógenos humanos, tais como o vírus da hepatite A (HAV) no plasma e outros líquidos, foi realizado por Casteel $^{25}$. Avaliou-se o efeito de porfirinas sintéticas sobre o HAV e o bacteriófago MS2 em plasma humano contendo porfirinas em solução salina tamponada com fosfato expostas à luz UV em $365 \mathrm{~nm}$. Foi obtido 99,9\% de inativação em ambos, HAV e MS2, mostrando que o método pode ser uma abordagem efetiva e segura de remoção de vírus não envelopados em meios aquosos. Entretanto, 
existem relatos de que os vírus envelopados com lipídeos são mais susceptíveis à PDI que cepas não-envelopadas.

$\mathrm{O}$ vírus da herpes simplex (HSV) está entre os agentes mais comuns responsáveis por infecções virais no homem e freqüentemente associadas com sintomas clínicos sérios, especialmente em pacientes imunocomprometidos, gestantes e recém-nascidos. Apesar disso, na última década somente 5 fármacos foram aprovados e clinicamente usados para tratamento dessas infecções. A emergente resistência dos vírus aos fármacos antivirais clássicos e os efeitos colaterais são as principais razões para um refinamento no desenvolvimento dos fármacos antivirais. Nesse sentido, uma rota sintética simples para derivados da meso-tetrafenilporfirina catiônica $\beta$-vinil substituída foi proposta e estudos preliminares mostraram fotoatividade contra HSV de um desses derivados, atingindo $99 \%$ de inativação do vírus depois de 15 min de irradiação ${ }^{26}$.

\section{Desinfecção do sangue}

O sangue humano é, por definição, o sistema suporte da vida, uma vez que contém as células necessárias para transporte de oxigênio, identificação/inativação patógena, além de proteínas e enzimas essenciais para a cicatrização de feridas e tecidos. As técnicas modernas de separação podem resultar em muitos produtos úteis em termos de reposição ou produtos terapêuticos. Entretanto, o controle de agentes infecciosos no suprimento de sangue é um requisito imprescindível e requer tratamento específico para que seu uso seja seguro. Na prática, existem muitos fatores que dificultam esse tratamento.

Tratamento fotodinâmico é um dos pouquíssimos métodos de esterilização conhecidos até o momento, que pode ser bem sucedido em concentrados de células vermelhas do sangue ${ }^{27}$. Na realidade, o uso da terapia fotodinâmica contra colonização patogênica é conhecido desde 1900 com os experimentos de $\mathrm{Raab}^{10}$, mas permaneceu relativamente inexplorada devido ao fácil acesso aos antibióticos. Entretanto, o uso indiscriminado de antibióticos nessa época promoveu a seleção de bactérias e fungos resistentes aos fármacos, quadro que foi agravado com a AIDS. Neste panorama a PDI apresenta-se como uma alternativa potencialmente ideal para descontaminação local, que é claro se estende para o uso nos produtos do sangue ${ }^{14}$.

Yersinia enterocolitica é um patógeno Gram (-) que exibe crescimento significativo a $4{ }^{\circ} \mathrm{C}$ e, portanto, constitui uma ameaça aos concentrados de células vermelhas do sangue que são estocados a essa temperatura. Porém, foi observada atividade bactericida considerável usando-se AM e vários de seus congêneres associados à iluminação em 615-645 $\mathrm{nm}^{28}$.

Por outro lado, o tratamento fotodinâmico de suspensões de células vermelhas do sangue (RBC) pode resultar em hemólise indesejada durante extensos períodos de estocagem a $1-6{ }^{\circ} \mathrm{C}$. Considerando-se que a hemólise pode ser mediada por um corante ligado à membrana, a quinacrina, uma molécula similar ao FS em estrutura, mas diferente com relação às propriedades de absorção de luz, foi testada como um inibidor para a ligação à membrana de RBC na fotoinativação de vírus e estudos de foto-hemólise. Os resultados sugeriram que o corante ligado à membrana é, em parte, responsável pela hemólise fotoinduzida ${ }^{29}$.

Besselink et al..$^{27}$ estudaram o efeito protetor da associação simultânea de dipiridamol e Trolox contra possível perda de potássio e ocorrência de hemólise a curto e longo prazo observada no tratamento fotodinâmico de RBC por determinados FS. Trolox (análogo hidrossolúvel do tocoferol) atua como captador de ROS além de prevenir a possível agregação das RBC induzida pelo tratamento fotodinâmico. Dipiridamol também é um captador de ROS além de ser um ligante da banda III, uma das proteínas-alvo das espécies reativas de oxigênio geradas durante a TFD. Assim, dipiridamol inibe o transporte de íons através da banda 3. Ambos podem conferir proteção às RBC sem comprometer a inativação viral. Ben-Hur et al. sugerem o uso da mistura de antioxidantes vitamina E, manitol e glutationa para evitar o problema de agregação das células ${ }^{30}$.

Devido ao advento da AIDS, tornou-se necessário a melhoria das técnicas de avaliação do sangue de doadores. Entretanto, devido à existência de períodos onde agentes infecciosos não podem ser detectados, é de grande importância a habilidade de desinfectar o sangue e seus derivados: plasma, plaquetas e concentrados de RBC. Torna-se necessário o uso de um procedimento padrão para possibilitar a desinfecção do sangue e seus produtos. Agentes fotodinâmicos baseados no núcleo fenotiazínico oferecem um excelente perfil com baixa toxicidade associada e efeitos colaterais no plasma. Azul de metileno é atualmente empregado em várias agências européias de desinfecção do plasma.

A contaminação viral não é o único fator na transmissão de doenças pelo sangue doado. Tem sido descrito que os patógenos intravasculares envolvidos em doenças tropicais podem ser inativados usando-se PDI ${ }^{14}$. Ftalocianina de silício catiônica (Pc4), por ex., pode mediar a inativação de Plasmodium falciparum e Trypanosoma cruzi na concentração de $2 \mu \mathrm{mol} / \mathrm{L}$ e uma fonte de irradiação de $25 \mathrm{mWcm}^{-2}$ 31,32. Devido a sua efetividade, Pc-4 tem sido usado como um composto líder na pesquisa contra a malária $^{33}$. Poucos estudos constam na literatura sobre os efeitos bactericidas desses compostos na presença de componentes do sangue. Assim, ftalocianinas de Si e seus derivados podem sensibilizar a inativação do vírus da estomatite vesicular, da malária e mesmo múltiplas formas do vírus da imunodeficiência humana ${ }^{34}$, sendo Pc4 um dos FS mais utilizados para essa aplicação.

Ambas as abordagens fotoquimioterapêutica e fotodinâmica para desinfecção do sangue empregam luz como fonte e energia para suas reações químicas de desinfecção, que podem ser classificadas como cicloaditivas ou fotooxidativas ${ }^{14}$.

\section{Periodontia}

Doença periodontal é causada por uma série de espécies de bactérias patogênicas que, junto com uma vasta gama de espécies compatíveis com o hospedeiro, formam complexos nos biofilmes subgengivais (placas) e são responsáveis pela inflamação clínica e destruição periodontal. Um FS pode ser injetado dentro da cavidade periodontal, seguido de iluminação com fibra ótica inserida dentro da área afetada. Essa técnica mantém o efeito bactericida confinado na lesão, de forma que a microflora benéfica em outros locais da boca pode permanecer intacta. De forma similar, o mesmo procedimento clínico poderia ser aplicado nas desinfecções de cáries na superfície dos dentes ${ }^{7}$. Os aspectos da fotobiologia e fototerapia aplicada às doenças periodontais bem como seu estado da arte são discutidos por Meisel e Kocher ${ }^{35}$.

Tem sido descrito que vários fotossensibilizadores podem matar bactéria oral in vitro. Azul de metileno, por ex., pode erradicar totalmente $C$. albicans da cavidade oral com administração tópica do corante ${ }^{36}$. Rovaldi et al. sugerem o uso de um potente derivado de clorina para reduzir diversas bactérias patogênicas na cavidade periodontal e que o método pode se tornar uma ferramenta importante para tratamento de doenças periodontais ${ }^{37}$.

\section{Desinfecção de água}

Purificação de água contaminada usando radiação solar na presença de FS e oxigênio dissolvido pode levar tanto à degradação de 
pesticidas quanto à morte de microorganismos ${ }^{38}$. Acher e colaboradores $^{39}$ usaram AM dissolvido homogeneamente em água para experimentos de desintoxicação em condições de laboratório e em uma escala de planta piloto. Uma desvantagem de tais sistemas com sensibilizadores dissolvidos homogeneamente é a necessidade de remover o FS da água após o tratamento. Em princípio, esse problema pode ser resolvido com sensibilizadores imobilizados em fase heterogênea. Foi descrita recentemente a preparação de compostos de zinco-porfirina imobilizados em poli(metilmetacrilato) (PMMA) para resolver esse problema ${ }^{38}$.

\section{Parasitas patogênicos humanos}

Parasitas humanos patogênicos também podem ser mortos pela combinação de FS e luz. Plasmodium falciparum, responsável pela malária, pode ser morto por PDI na presença de um derivado de $\mathrm{N}$ (4-butanol)feoforbídeo ${ }^{40}$ e por ftalocianinas de silício, tais como $\mathrm{Pc}^{33}$. O parasita responsável pela doença de Chagas, Trypanosoma cruzi, também pode ser morto pela combinação de luz e fotossensibilizadores como hematoporfirina e ftalocianinas ${ }^{41}$. Ovos de helmintos humanos em água de esgoto podem ser inativados por uma porfirina catiônica meso-substituída e luz ${ }^{42}$.

\section{Tratamento antimicrobiano de alimentos}

Os métodos e tecnologias usados para controle bacteriano em alimentos nem sempre são suficientemente eficientes e inteiramente isentos de danos ao homem e ao ambiente. As bem conhecidas tecnologias não térmicas podem alterar a estrutura de proteínas e polissacarídeos, causando mudanças na textura, aparência física e funcionalidade dos alimentos. Por ex., ultra-som de alta intensidade pode desnaturar proteínas e produzir radicais livres com conseqüente alteração no sabor de alimentos gordurosos ou contendo frutas. Além disso, altas doses de radiação nãoionizante podem causar leves mudanças de cor nas carnes. Fotossensibilização tem sido proposta como um método de inativação de micróbios patogênicos com bom custo-benefício e ecologicamente correto uma vez que envolve dois elementos nãotóxicos, corante e luz em ambiente oxigenado, induzindo destruição total dos microorganismos, constituindo-se em uma promissora tecnologia biofotônica ${ }^{43,44}$.

\section{FOTOSSENSIBILIZADORES}

\section{Porfirinas}

Os fotossensibilizadores mais utilizados em TFD do câncer são os derivados de hematoporfirina sendo Photofrim ${ }^{\circledR}$ (Canadá) o mais conhecido, tendo sido autorizado para uso clínico em 1998 nos Estados Unidos seguido por Canadá, Holanda, França, Alemanha, Japão etc ${ }^{8}$. Os fotossensibilizadores correspondentes produzidos na Alemanha e Rússia são, respectivamente, Photosan ${ }^{\circledR}$ e Photogem ${ }^{\circledR 45-47}$. Ambos apresentam características químicas, fotofísicas e de diagnóstico bem como características terapêuticas semelhantes, porém não idênticas ao Photofrin ${ }^{\circledR}$. Esses três fotossensibilizadores são de primeira geração e consistem de mistura de monômeros, dímeros e oligômeros de derivados de hematoporfirina.

\section{Clorinas}

As clorinas são porfirinas reduzidas. A clorina e é uma forma derivada da clorofila $a$ que apresenta duas importantes propriedades: maior rendimento quântico de formação de oxigênio singlete e intensa banda de absorção em comprimentos de onda maiores (650-660 nm) que as porfirinas $(610-630 \mathrm{~nm})$, onde os tecidos biológicos são mais transparentes à luz. Photodithazine (Rússia) é uma clorina e ${ }_{6}$ modificada através da adição de N-metil-D-glicosamina como um agente solubilizante e estabilizante, tornando-a hidrossolúvel, capaz de penetrar nas células através das membranas biológicas ${ }^{48,49}$. Visudyne ${ }^{\circledR}$, uma benzoporfirina, foi recentemente aprovada para tratamento da degeneração macular da retina, uma doença relacionada à idade e que afeta $40 \%$ de pessoas acima de $75 \operatorname{anos}^{50}$.

\section{Ácido 5-aminolevulínico}

Uma outra abordagem muito usada em TFD é baseada na acumulação endógena de PpIX induzida pela administração tópica ou sistêmica de ALA, usado como um precursor de FS (Figura 5). Essa abordagem terapêutica está se tornando uma opção no tratamento de doenças, incluindo lesões tumorais e pré-tumorais, desordens vasculares proliferativas e foi recentemente aprovada pelo "Food and Drug Administration" dos Estados Unidos e na Europa para queratose actínica e carcinomas de células basais ${ }^{51}$.

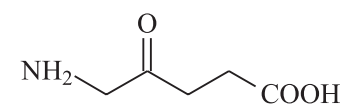

Figura 5. Estrutura química do ácido 5-aminolevulínico (ALA)

Embora formação altamente regulada de protoporfirina IX (PpIX) exista em quase todas as células nucleadas, PpIX acumula preferencialmente em tecidos com alta atividade celular ${ }^{52}$. PpIX pode ser sintetizada em todas as células contendo mitocôndria ${ }^{53}$. O fenômeno de acumulação do FS em tecidos doentes não é específico para doenças neoplásicas ou pré-neoplásicas. A síntese do ALA é normalmente controlada com rigor pela enzima ALAsintetase, provavelmente através do nível intracelular de heme. ALA, quando fornecido para a célula, subverte esse controle e resulta na acumulação da PpIX, que é convertida em heme pela ferroquelatase pela adição de ferro ao núcleo da PpIX. Uma vez que essa conversão é um processo lento ${ }^{54}$, altos níveis de PpIX são encontrados no tecido, embora para produzir um efeito fotodinâmico necessite da exposição à luz ${ }^{55,56}$. Há várias vantagens na fotosensibilização por PpIX induzida pelo ALA, uma delas é que o organismo elimina PpIX rapidamente, o que limita o risco da fotossensibilidade a 1-2 dias.

\section{Ftalocianinas}

Embora as ftalocianinas possam ser consideradas como sendo derivadas de porfirinas, seu caráter aromático grandemente aumentado explica a absorção mais intensa desses compostos no infravermelho próximo comparada àquela dos núcleos de porfirina originais. Além disso, as rotas de síntese relativamente diretas de ftalocianinas (em comparação com porfirinas) fornecem uma larga gama de compostos em termos do átomo de metal/semimetal central (Al, Ga, Si, Zn) e funcionalidade da cadeia lateral. Como FS, as ftalocianinas fornecem alto rendimento de produção de oxigênio singlete, maior que de um FS padrão como o AM. Ftalocianinas têm mostrado grande potencial na área de desinfecção dos produtos do sangue. Em termos de relação estrutura-atividade para ftalocianinas, parece haver pouca correlação entre a potência antiviral e o átomo central da ftalocianina, pois isso tem mais efeito sobre o rendimento de oxigênio singlete que sobre seletividade e ligação ${ }^{14}$. 


\section{Fenotiazínicos}

Os corantes fenotiazínicos exibem intensa absorção de 600$660 \mathrm{~nm}$, região do espectro útil em TFD por estar na "janela terapêutica" requerida para a eficiente penetração da luz nos tecidos ${ }^{57}$. Azul de metileno tem sido usado clinicamente no tratamento de câncer de bexiga e, recentemente, contra tumores de esôfago inoperáveis, virulências da pele, psoríase e adenocarcinomas ${ }^{15}$.

Um estudo comparativo da citotoxicidade do AM no escuro em células normais e tumorais verificou que esse corante é mais citotóxico em células tumorais ${ }^{58,59}$. O fato de que tanto células MDR como cepas de bactérias resistentes a múltiplos antibióticos também são sensíveis ao corante ${ }^{6}$ sugere que AM pode ser usado como um agente quimioterapêutico.

Azul de metileno é também empregado como FS em desinfecção viral do sangue. Entretanto, tanto em TFD de câncer como nos recentes regimes antimicrobianos, os corantes fenotiazínicos comerciais têm mostrado a desvantagem de uma toxicidade inerente (no escuro), o que causa uma diminuição da eficiência terapêutica. Desta forma, têm sido realizados estudos de desenvolvimento racional para a síntese de análogos do $\mathrm{AM}^{18,56}$.

\section{Riboflavina}

Vitamina B2, ou riboflavina (Figura 6), essencial na dieta humana, é um agente comprovadamente não tóxico que pode ser usado na fotodesinfecção dos produtos do sangue, uma vez que nesse processo as principais preocupações são os prováveis efeitos colaterais nos receptores do sangue. A fotoquímica da riboflavina é bem conhecida, bem como suas interações com ácidos nucléicos ${ }^{60}$. Embora esse tipo de estudo esteja apenas em sua fase inicial, sabe-se que riboflavina é ativa em cada um dos principais componentes do sangue sem dano significante a essas estruturas, inclusive no uso em $\mathrm{RBC}^{14}$.<smiles>Cc1cc2nc3c(=O)[nH]c(=O)nc-3n(CC(O)C(O)O)c2cc1C</smiles>

Figura 6. Estrutura química da riboflavina

\section{Hipericina}

A hipericina é um pigmento fotoativo natural produzido por plantas do gênero Hypericum da família Guttiferae. indicada em quadros de distúrbios psicovegetativos, estados depressivos leves e moderados, medo e/ou agitação emocional. Além disso, possui propriedades antiinflamatórias, anti-sépticas, antiinfecciosas, antivirais, cicatriza a varicela, estimula a circulação sanguínea e elimina os hematomas. O composto exibe uma potente atividade fototóxica antitumor in vitro e in vivo. Hipericina é provavelmente o mais potente FS encontrado na natureza. Relatos recentes tem mostrado que é possível explorar a<smiles></smiles>

Figura 7. Estrutura química da hipericina fotoatividade da hipericina no tratamento de psoríase e outras doenças da pele $^{61}$. Atualmente, a hipericina produzida sinteticamente tem sido estudada como uma nova geração de fármacos para utilização em TFD e alguns resultados indicam que este FS pode induzir tanto a apoptose quanto a necrose de células tumorais ${ }^{62}$.

\section{Xantenos}

Xantenos são compostos cíclicos com três anéis aromáticos em arranjo linear com um átomo de oxigênio no centro do anel, que absorvem luz na região do visível. Uma característica importante dos corantes xantenos é que não se ligam à membrana celular e localizam-se no citoplasma. Alguns exemplos de xantenos são Rosa de Bengala, Eosina Y, Fluoresceína e Eritrosina B. Rosa de Bengala é um haleto derivado da fluoresceína que tem sido usado em oftalmologia como um corante para diagnóstico de várias doenças externas ao olho. Como um FS, Rosa de Bengala pode matar microorganismos, tais como vírus, bactérias e protozoários, além de induzir efeitos fotodinâmicos in vitro em RBC, cardiomiocitos e células epiteliais do pigmento da retina. Em um ambiente aquoso contendo nucleotídeos, o mecanismo fotodinâmico da Rosa de Bengala sob irradiação em $532 \mathrm{~nm}$ é predominantemente do tipo II, gerando 80\% de oxigênio singlete e os restantes $20 \%$ de ânion superóxido ${ }^{63,64}$. Eritrosina tem atividade antimicrobial contra bactérias orais Gram (+) e Gram (-). Esse corante é usado para corar o agente etiológico das doenças orais comuns (placa dentária), porém o único trabalho usando eritrosina como um FS em odontologia foi recentemente publicado por Wood et al. ${ }^{65}$. Eritrosina tem uma vantagem sobre outros fotossensibilizadores em desenvolvimento uma vez que tem completa aprovação para uso na boca ${ }^{65}$. Eosina Y é um derivado tetrabromo da fluoresceína e pode ser usado para corar o citoplasma, o colágeno e as fibras musculares para exame ao microscópio. A inativação de E. coli. por corantes como AM, Rosa de Bengala e eosina imobilizados ou recobrindo suportes insolúveis, foi estudada como uma alternativa para desinfecção de água ${ }^{66}$.

\section{CONCLUSÕES}

O uso de antibióticos sistêmicos pode ser limitado em lesões traumáticas e queimaduras que contêm quantidade significante de tecido não perfundido, devido ao comprometimento da circulação capilar. Por outro lado, a aplicação tópica do FS na área infectada permite que o FS entre diretamente em contato com os micróbios sem ser distribuído às células do hospedeiro. Uma vez que o FS catiônico se liga rapidamente aos micróbios e é lentamente capturado pelas células hospedeiras, isso permite uma seletividade temporal favorável aos microrganismos. Dessa forma, se a luz é aplicada relativamente rápido após a administração do FS, o dano colateral para o tecido hospedeiro será minimizado.

Existe uma infinidade de aplicações da PDI, especialmente no caso de infecções. Isto se torna especialmente importante devido ao alarmante crescimento da resistência a antibióticos e a necessidade de métodos alternativos de tratamento local tornam-se necessários. Além disso, em muitas infecções localizadas, antibióticos administrados de forma oral ou sistêmica não são particularmente efetivos, ou porque as bactérias estão infectando um tecido que não é bem perfundido ou porque as bactérias estão presentes no tecido como um biofilme, o que reduz dramaticamente a susceptibilidade ao antibiótico. Para que PDI possa ser usada no futuro para combater infecções localizadas difíceis de tratar, é necessário que o FS seja capaz de ser administrado de forma local, tópica ou intracavidade e, depois de um tempo adequado, proceder à irradiação da área infectada com luz em dose e comprimento de onda 
adequados, com fibra ótica, ponta difusora e outros ou por iluminação direta da área exposta cirurgicamente.

Dois grandes grupos de doenças em que FS e luz podem ser facilmente entregues no local das infecções por PDI são: infecções associadas a trauma cujas manifestações clínicas variam desde infecções superficiais causadas por várias bactérias Gram (+) e Gram (-) até necrose e gangrena e o segundo grupo inclui infecções em cavidades do corpo e superfícies que geralmente respondem mal a antibióticos sistêmicos, por ex., otite média, doenças periodontais, infecções do trato urinário e viroses ${ }^{6}$.

Em termos de química envolvida na desinfecção do sangue, os agentes fotodinâmicos baseados no núcleo fenotiazínico oferecem um excelente perfil antimicrobiano com baixa toxicidade no plasma e poucos efeitos colaterais associados. Pesquisas estão sendo feitas na área, principalmente visando uma efetiva remoção dos fotossensibilizadores pós-tratamento. Azul de metileno já é empregado por várias agências européias de desinfecção do plasma.

\section{AGRADECIMENTOS}

$\mathrm{O}$ autor agradece a leitura deste texto e as sugestões do Dr. H. Imasato, do Dr. C. A. Montanari e do MS. D. Bonini.

\section{REFERENCIAS}

1. Gad, F.; Zahra, T.; Hasan; T.; Hamblin, M. R.; Antimicrob. Agents Chemother. 2004, 48, 2173.

2. Lambrechts, S. A. G.; Aalders, M. C. G.; Marle, J. V.; Antimicrob. Agents Chemother. 2005, 49, 2026.

3. Demidova, T. N.; Hamblin, M. R.; Antimicrob. Agents Chemother. 2005, 49, 2329.

4. Carré, V.; Gaud, O.; Sylvain, I.; Bourdon, O.; Spiro, M.; Blais, J.; Granet, R.; Krausz, P.; Guilloton, M.; J. Photochem. Photobiol., B 1999, 48, 57.

5. Machado, A. E. H.; Quim. Nova 2000, 23, 237.

6. Demidova, T. N.; Hamblin, M. R.; Int. J. Immunopathol. Pharmacol. 2004, 17,245 .

7. Hamblin, M. R.; Hasan, T.; Photochem. Photobiol. Sci. 2004, 3, 436.

8. Capella, M. A. M.; Capella, L. S.; J. Biomed. Sci. 2003, 10, 361.

9. Wainwright, M.; J. Antimicrob. Chemother. 1998, 42, 13.

10. Raab, O.; Z. Biol. 1900, 39, 524.

11. von Tappeiner, H.; A. Jesionek, U.; Dtsch. Arch. Klin. Med. 1904, 80, 427.

12. Policard, A.; CR Soc. Biol. 1924, 91. 1423.

13. Wainwright, M.; Chem. Soc. Rev. 2002, 31, 128.

14. Wainwright, M.; Curr. Med. Chem. 2002, 9, 127.

15. Orth, K.; Ruck, A.; Beck, G.; Stanescu, A.; Beger, H. G.; Chirurg 1995, $66,1254$.

16. Maisch, T.; Bosl, C.; Szeimies, R.-M.; Lehn, N.; Abels, C.; Antimicrob. Agents Chemother. 2005, 49, 1542.

17. Zeina, B.; Greenman, J.; Corry, D.; Purcell, W. M.; Br. J. Dermatol. 2002, 146, 568.

18. Tardivo, J. P.; Giglio, A. D.; Oliveira, C. S.; Gabrielli, D. S.; Junqueira, H. C.; Tada, D. B.; Severino, D.; Turchiello, R. F.; Baptista, M. S.; Photodiagn. Photodyn. Ther. 2005, 2, 175.

19. Wilder-Smith, C. H.; Wilder-Smith, P.; Grosjean, P.; van den Bergh, H.; Woodtli, A.; Monnier, P.; Dorta, G.; Meister, F.; Wagnieres, G.; Lasers Surg. Med. 2002, 31, 18.

20. Meffert, H.; Gaunitz, K.; Gutewort, T.; Amlong, U. J.; Dematol. Monatsschr. 1990, 176, 597.

21. Hongcharu, W.; Taylor, C. R.; Chang, Y.; Aghassi, D.; Suthamjariya, K.; Anderson, R. R.; J. Invest. Dermatol. 2000, 115, 183.

22. Strakhovskaya, M. G.; Belenikina, N. S.; Ivanova, E. V.; Chemeris, Y. K.; Stranadko, E. F.; Microbiology 2002, 71, 298.

23. Rex, J. H.; Rinaldi, M. G.; Pfaller, M. A.; Antimicrob. Agents Chemother. 1995, 39, 1 .

24. Shikowitz, M. J.; Abramson, A. L.; Freeman, K.; Steinberg, B. M.; Nouri, M.; Laryngoscope 1998, 108, 962.

25. Casteel, M. J.; Jayaraj, K.; Gold, A.; Ball, L. M.; Sobsey, M. D.; Photochem. Photobiol. 2004, 80, 294.

26. Silva, E. M. P; Giuntini, F.; Faustino, M. A. F.; Tome, J. P. C.; Neves, M. G. P. M. S.; Tomé, A. G.; Silva, A. M.; Santana-Marques, M. G.; FerrerCorreia, A. J.; Cavaleiro, J. A. S.; Caeiro, M. F.; Duarte, R. R.; Tavares, S.
A. P.; Pegado, I. N.; Almeida, B.; De Matos, A. P. A.; Valdeira, M. L.; Bioorg. Med. Chem. Lett.. 2005, 15, 3333.

27. Besselink, G. A. J.; van Engelenburg, F. A. C.; Ebbing, I. G.; Hilarius, P. M.; de Korte, D.; Verhoeven, A. J.; Vox Sanguinis 2003, 85, 25.

28. Wainwright, M.; Phoenix, D. A.; Smillie, T. E.; Wareing, D. R.; J. Chemother. 2001, 13, 503.

29. Wagner, S. J.; Skripchenko, A.; Thompson-Montgomery, D.; Photochem. Photobiol. 2002, 76, 514.

30. Ben-Hur, E.; Barshtein, G.; Chen, S.; Yedgar, S.; Photochem. Photobiol. 1997, 66, 509.

31. Lustigman, S.; Ben-Hur, E.; Transfusion 1996, 36, 543.

32. Gottleib, P.; Margolis-Nunno, H.; Robinson, R.; Shen, L. G.; Chimezie, E.; Horowitz, B.; Ben-Hur, E.; Photochem. Photobiol. 1996, 63, 562.

33. Zhao, X. J.; Lustigman, S.; Li, Y. S.; Kenney, M. E.; Ben-Hur, E.; Photochem. Photobiol. 1997, 66, 282.

34. Kaestner, L.; Juzenienea, A.; Moan, J.; Photochem. Photobiol. Sci. 2004, 3, 981 .

35. Meisel, P.; Kocher, T.; J. Photochem. Photobiol., B 2005, 79, 159.

36. Teichert, M. C.; Jones; J. W.; Usacheva, M. N.; Biel, M. A.; Oral Surg., Oral Med., Oral Pathol. Oral Radiol. Endod. 2002, 93, 155.

37. Rovaldi, C. R.; Pievsky, A.; Sole, N. A.; Friden, P. M.; Rothstein, D. M.; Spacciapoli, P.; Antimicrob. Agents Chemother. 2000, 44, 3364.

38. Faust, D.; Funken, K.-H.; Hornek, G.; Millow, B.; Ortner, J.; Sattlegger, M.; Schafer, M.; Schmitz, C.; Solar Energy Mater. Sol. Cells 1999, 65, 71.

39. Acher, A. J.; Fischer E.; Tornheim R.; Manor Y. Em Proc. 8th Int. Symp. Sol. Thermal Conc. Technol.; Becker, M.; Bohmer, M., eds.; C. F. Muller Verlag: Heidelberg, 1997.

40. Grellier, P.; Santus, R.; Mouray, E.; Agmon, V.; Maziere, J. C.; Rigomier, D.; Dagan, A.; Gatt, S.; Schrevel J.; Vox Sanguinis 1997, 72, 211.

41. Kliukiene, R.; Maroziene, A.; Cenas, N.; Becker, K.; Blanchard, J. S.; Biochem. Biophys. Res. Commun. 1996, $218,629$.

42. Alouini, Z.; Jemli, M.; J. Environ. Monit. 2001, 3, 548.

43. Luksiene, Z.; Peciulyte, D.; Jurkoniene, S.; Puras, R.; Food Technol. Biotechnol. 2005, 43, 335 .

44. Luksiene, Z.; Food Technol. Biotechnol. 2005, 43, 441.

45. Menezes, P. F. C.; Melo, C. A. S.; Bagnato, V. S.; Imasato, H.; Perussi, J. R.; Laser Physics 2005, 15, 435.

46. Menezes, P. F. C.; Melo, C. A. S.; Bagnato, V. S.; Imasato, H.; Perussi, J. R.; Laser Physics 2004, 14, 1214.

47. Ferreira, J.; Kurachi, C.; Moriyama, L. T.; Menezes, P. F. C.; Perussi, J. R.; Sibata, C.; Zucoloto, S.; Castro, O.; Silva J. R.; Bagnato, V. S.; Laser Phys. Lett. 2006, 3, 91.

48. Reshetnickov, A.V.; Ponomarev, G. V.; Abakumova, O. Y.; Tsvetkova, T. A.; Karmenyan, A. V.; Rebeko, A. G.; Baum, R. P.; Proceedings of SPIE 2000, 3909, 124.

49. Ivanov, A. V.; Reshetnickov, A. V.; Ponomarev, G. V.; Proceedings of SPIE 2000, 3909, 131.

50. Simplício, F. I.; Maionchi, F.; Hioka, N.; Quim. Nova 2002, 25, 801

51. Zeitouni, N. C.; Oseroff, A. R.; Shieh, S.; Mol. Immunol. 2003, 39, 1133.

52. Berger, Y.; Greppi, A.; Siri, O.; Neier, R.; Juillerat-Jeanneret, L.; J. Med. Chem. 2000, 43, 4738.

53. Babilas, P.; Schacht, V.; Liebscg, G.; Wolfbeis, O. S.; Landthaler, M.; Szeirinies, R. M.; Abels, C.; Br. J. Cancer 2003, 88, 1462.

54. Correa García, S.; Casas, A.; Perotti, C.; Batlle, A.; Bermúdez Moretti, M.; Br. J. Cancer 2003, 89, 173 .

55. Kennedy, J. C.; Pottier, R. H.; Pross, D. C.; J. Photochem. Photobiol., B 1990, 6, 143.

56. Fukuda, H.; Battle, A. M. C.; Riley, P. A.; Int. J. Biochem. 1993, 25, 1407.

57. Wainwright, M.; Grice, N. J.; Pye, L. E. C.; Dyes Pigm. 1999, 42, 45.

58. Kirszberg, C.; Rumjanek, V. M.; Capella, M. A. M.; Cancer Chemother. Pharmacol. 2005, 56, 659 .

59. Menezes, P. F. C.; Bernal, C.; Imasato, H.; Bagnato, V. S.; Perussi, J. R.; Laser Physics 2007, 17, 468.

60. Souza, A. C. S.; Ferreira, C. V.; Jucá, M. B.; Aoyama, H.; Cavagis, D. M.; Peppelenbosch, M. P.; Quim. Nova 2005, 28, 887.

61. Kamuhabwa, A. R.; Roelandts; R.; de Witte, P. A.; J. Photochem. Photobiol., B 1999, 53, 110.

62. Agostinis, P.; Vantieghema, A.; Merlevede, W.; Witte, P. A. M.; Int. J. Biochem. Cell Biol. 2002, 34, 221.

63. Tseng, S. C. G.; Feenstra, R. P. G.; Watson, B. D.; Investigative Ophthalmology \& Visual Science 1994, 35, 3295.

64. Schafer, M.; Schmitz, C.; Facius, R.; Horneck, G.; Milow, B.; Funken K.H.; Ortner, J.; Photochem. Photobiol. 2000, 71, 514.

65. Wood, S.; Metcalf, D.; Devine, D.; Robinson, C.; J. Antimicrob. Chemother. 2006, 57, 680 .

66. Savino, A.; Angeli, G.; Water Res. 1985, 19, 1465. 